EXTENDED REPORT

\title{
Delay in presentation to hospital for surgery for congenital and developmental cataract in Tanzania
}

\author{
J Mwende, A Bronsard, M Mosha, R Bowman, R Geneau, P Courtright
}

Br J Ophthalmol 2005;89:1478-1482. doi: 10.1136/bjo.2005.074146

See end of article for authors' affiliations ......................

Correspondence to: Dr Paul Courtright, Kilimanjaro Centre for Community

Ophthalmology, Tumaini

University, PO Box 2254,

Moshi, Tanzania;

pcourtright@kcco.net

Accepted for publication 6 June 2005
Background: Childhood cataract is a leading cause of blindness in children in eastern Africa. High quality surgical services have been established at a few tertiary facilities in the region; however, there appears to be delay in presentation to hospital.

Methods: Parents or guardians of all children presenting to KCMC Hospital or CCBRT Hospital with congenital (recognised since birth or within the first year) or developmental (cataract leading to reduction in vision after 1 year of age) cataract were interviewed regarding the actions taken (and timing of these) before coming to hospital. Demographic information was also collected. For analysis children were grouped as either late presenters (more than 12 months after recognition) or not late presenters (within 12 months of recognition) and predictors of late presentation were assessed.

Results: Among 178 children (74 congenital cataract and 104 developmental cataract) analysed, the mean delay between recognition by the caregiver and presentation to hospital was 34 months, almost 3 years. The median delay was 18 months -9 months for congenital cataract and 24 months for developmental cataract. Long delay in presentation was associated with having developmental cataract, living far from the hospital, and low socioeducational status of the mother. Among children with congenital cataract, having another sibling increased the likelihood of early presentation.

Conclusion: Delay in presentation remains a significant problem for children needing surgery for congenital or developmental cataract. Parents who have multiple children may be more likely to seek early treatment, possibly because their expectations of achievable sight at a young age are based on previous experience of their older children. Educational efforts should aim to reach the most "unreachable" (those living the furthest from the hospital and having the lowest socioeducational status of the mother).
C ataract is one of the main causes of global blindness and low vision in children; it is estimated that there are 200000 children worldwide blind from cataract; a further 20000-40000 children are born each year with congenital cataract. ${ }^{1}$ Globally the incidence of cataract in childhood has been reported as $1-15 / 10000$ live births. ${ }^{23}$ Studies that were done in schools for the blind in west Africa, south India, and Chile showed that lens abnormalities contributed to $15.5 \%, 7.4 \%$, and $9.2 \%$ of all blindness respectively. ${ }^{4}$ In eastern Africa studies done in schools for the blind in Malawi, Kenya, and Uganda found that $13.1 \%$, $9.1 \%$, and $27.6 \%$ of children surveyed $(n=491)$, respectively, had an unoperated cataract. ${ }^{5}$ More recently, in Ethiopia, unoperated cataract or aphakia accounted for $9.2 \%$ of blindness in schools for the blind. ${ }^{6}$ With significant reductions in preventable causes of blindness (for example, measles and vitamin A deficiency) cataract is becoming the major cause of treatable blindness in children.

Research in Malawi demonstrated that many blind children and those with low vision who might benefit from surgical intervention did not have an operation. ${ }^{8}$ Most parents did not know what was involved in surgery nor did they understand the cause of blindness of their children.

Management of congenital cataract depends on the aetiology and on the degree of visual interference. Severe bilateral cataracts with significant obstruction of the visual axis must be treated and surgery is recommended as soon as possible after discovery. Ideally cataracts should be removed before 3 months of age.

In unilateral congenital cataract cases the prognosis for useful vision following surgery depends on prompt restoration of a clear visual axis, correction of aphakia, and aggressive treatment of amblyopia.
A retrospective review of 118 children receiving cataract surgery in Kenya showed that two thirds of cases were boys and only $23.7 \%$ were under the age of 2 years. ${ }^{9}$ There are no data on prevalence and incidence of childhood cataract in Tanzania. Given a population of 35 million, a birth rate of 42/ 1000 , and an estimated six to nine bilateral cataract cases per 10000 live births there would be 882-1323 children with congenital cataract born per year. There are two facilities for surgical services (Kilimanjaro Christian Medical Centre in Moshi and CCBRT Hospital in Dar es Salaam) and the total number of non-traumatic cataract surgeries performed in 2001 in both facilities was approximately 250 . Few people in Tanzania are aware of childhood (non-traumatic) cataract; children are frequently brought to the hospital after amblyopia has already developed. Some children are enrolled in schools for the blind rather than offered surgery.

We sought to determine delay in presentation and factors associated with this delay among children with childhood (non-traumatic) cataract. In particular, we sought to determine ( 1 ) the period of delay between first recognition of an abnormality (by the parents/guardians) and surgical intervention, (2) who in the family or community first detected the cataract, and (3) what sociodemographic factors predict delay in presentation to hospital.

\section{METHODS}

The research was conducted at Kilimanjaro Christian Medical College Hospital (KCMC) in Moshi and the Comprehensive Community Based Rehabilitation in Tanzania (CCBRT)

Abbreviations: CCBRT, Comprehensive Community Based Rehabilitation in Tanzania; KCMC, Kilimanjaro Christian Medical College Hospital 


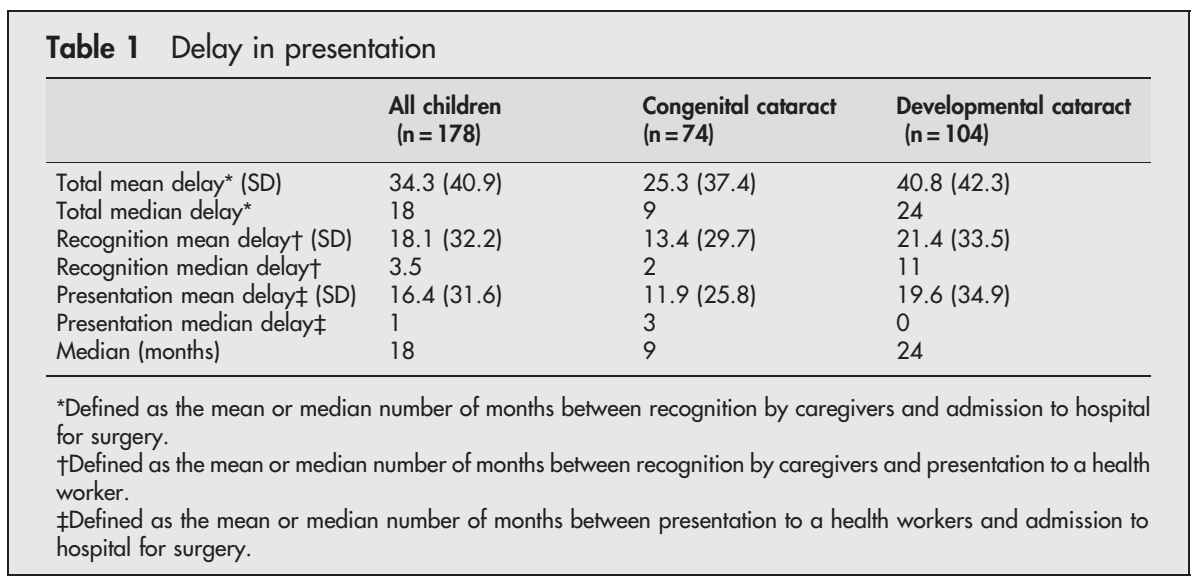

hospital in Dar es Salaam. The study population comprised all children under the age of 16 presenting with congenital and/ or developmental cataract during the period August 2002 to July 2004 at KCMC and from March to May 2003 at CCBRT Hospital. Ethical approval for the study was obtained from the ethics committee at Tumaini University. Informed consent was requested of caregivers before interview.

Caregivers presenting with children having cataract (nontraumatic) were interviewed immediately on admission and before surgery using a standardised, pretested questionnaire. Pretesting was carried out among all children presenting to KCMC Hospital in the 1 month before the start of the study. Interviews covered basic sociodemographic information of the household and a series of questions related to the steps the caregivers took before coming to hospital. For the purpose of this study, we defined socioeducational status as a combination of two separate questions related to occupation and education of the mother and father; these were combined to become a variable with the options of (a) illiterate farmer, (b) literate farmer, or (c) literate nonfarmer. Those children whose caregivers noticed the cataract when the child was below 1 year of age were classified as congenital cataract in this study, and those who had a history of good vision since birth and developed a cataract after 1 year of age were classified as developmental cataract. We defined early presentation as a period of 12 months or fewer between the time of recognition by the caregiver and presentation to hospital. Late presentation was defined as over 12 months. Separately, we divided delay into two parts: "recognition to presentation delay" being the number of months between the recognition by the caregiver and presentation of the child to a health provider; and "presentation to treatment delay" being the number of months between diagnosis of the abnormality by a health provider and presentation at hospital. "Total delay" was the total number of months between recognition of the abnormality by the caregiver and treatment at hospital. Data collected were entered and coded in SPSS Version 10 and odds ratios (95\% confidence intervals) were calculated. Student's $t$ test was used for continuous variables.

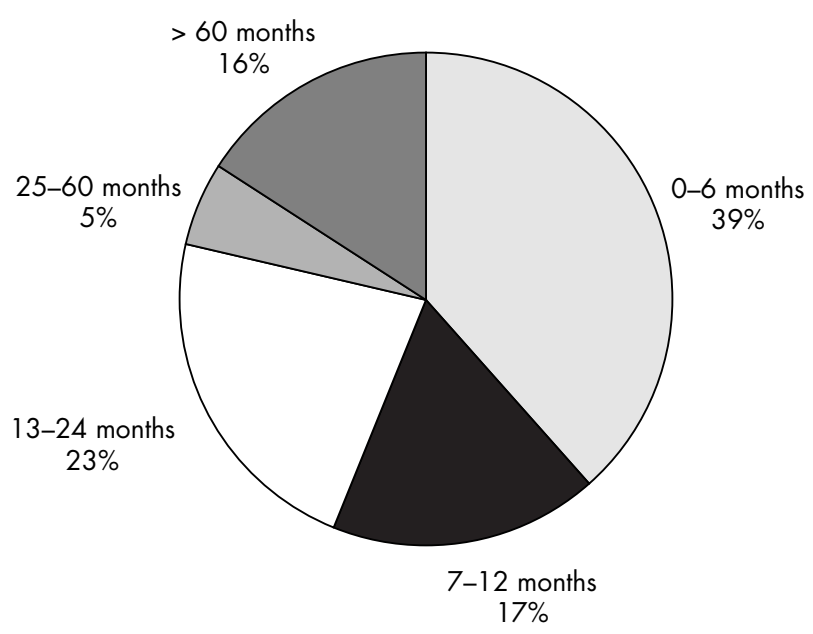

Figure 1 Delay in presentation to hospital for surgery for congenital cataract.

\section{RESULTS}

During the study period there were approximately 230 children who presented with congenital or developmental cataract. Children brought to hospital from schools for the blind (estimated to be around 30-40 children) could not be enrolled in the study since teachers unfamiliar with their history before school enrolment brought them. In addition, about 10 children were not interviewed since the interviewer was absent during their first visit to hospital. Of the 180 study cases with childhood cataract in the study, 99 (55\%) were boys and 81 (45\%) were girls. Ninety children came from the eight districts of Kilimanjaro and Arusha regions that are within easy reach to Moshi (site of KCMC) or from the six districts of Pwani Region and Dar es Salaam, within easy reach to Dar es Salaam (site of CCBRT), with the remainder from more distant districts. According to our definition, 75 of the children had congenital cataract and 105 had developmental cataract.

\begin{tabular}{|c|c|c|c|}
\hline & $\leqslant 12$ months & $>12$ months & \\
\hline Cataract & $74(41.5)$ & $104(58.4)$ & OR $(95 \% \mathrm{Cl})$ \\
\hline $\begin{array}{l}\text { Congenital } \\
\text { Developmental }\end{array}$ & $\begin{array}{l}41(55.4) \\
33(31.7)\end{array}$ & $\begin{array}{l}33(44.5) \\
71(68.2)\end{array}$ & $\begin{array}{l}2.67(1.38 \text { to } 5.28) \\
p=0.002\end{array}$ \\
\hline
\end{tabular}




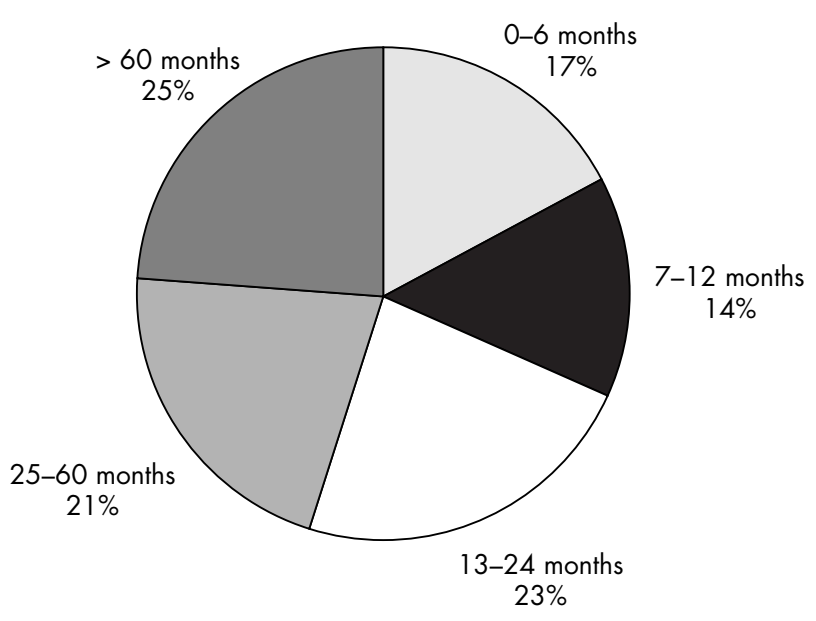

Figure 2 Delay in presentation to hospital for surgery for developmental cataract.

Data on delay were insufficient for two children who were removed from further analysis. The mean recognition to presentation delay was 18.1 months while the mean presentation to treatment delay was 16.4 months; thus, the overall mean total delay between recognition of an abnormality by caregivers and presentation to the hospital for surgery was 34.3 months (median 18 months) (table 1). Among the children $74(41.6 \%)$ presented to hospital within 12 months of recognition by the parent; the remaining 104 (58.4\%) presented to hospital from $12-170$ months after recognition of the abnormality by the caregiver. Thirty seven children were brought to the hospital 5 years or more after recognition of the abnormality in the household.

Children with congenital cataract were 2.67 times (95\% CI 1.38 to 5.28 ) more likely to be brought in within 12 months of recognition by the caregivers compared to children with developmental cataract (table 2). There was no statistically significant difference in early versus late presentation by sex, religion, family history of cataract, or laterality of cataract (table 3). Children living near the hospital were 1.97 times (95\% CI 1.02 to 3.79 ) more likely to come early compared to children living far from the hospital. Finally, there was an association between mother's socioeducational status and delay in presentation; children of mothers with higher socioeducational status were more likely to bring their children within 12 months of recognition.

The delay in presentation in children with developmental cataract was significantly longer (mean 40.8 months; median 24 months) than the delay in presentation in children with congenital cataract (mean 25.3 months; median 9 months) (figs 1 and 2). Further analysis of the reasons for delay in presentation were carried out separately for children with congenital and developmental cataract. Among children with congenital cataract $(n=74)$ the same factors remained associated with delay in presentation; children living near the hospital were 3.99 times (95\% CI 1.48 to 10.79) more likely to come early compared to children living far from the hospital (table 3 ). In addition, children coming from households with two or more children (the child had an older sibling) were 4.4 times more likely to be brought within 12 months. Among children with developmental cataract $(n=104)$ only the trend between mother's socioeducational status and delay in presentation was noted. We detected no statistically significant association between laterality and delay.

Girls tended to be brought in later than boys (difference not statistically significant). The variation in delay was significantly greater in girls than boys (table 4 ).

\section{DISCUSSION}

Blindness caused by childhood cataract in developing countries is primarily a result of inadequate or timely use of surgical services. ${ }^{7}$ The shorter the duration between onset of visually impairing cataract and surgery, the greater the likelihood that surgical intervention will lead to a good visual outcome. Children with congenital cataract are more likely to have mature cataracts leading to severe visual deprivation compared to children with developmental cataract in whom the cataract may develop more gradually. Regardless of the type of cataract, early presentation is important for visual outcome. The excessive delay in presentation in our study population suggests that there are barriers to presentation to surgery, including awareness of the problem (and surgical interventions), access to surgical services, or acceptance of surgical services. The major delay occurred between recognition and presentation (the time the caregivers recognised the problem and sought care from a health worker) rather than between the presentation to treatment delay. This suggests that the primary barriers exist at the community level rather than the provider level; however, presentation to treatment delay is still too long. The wide variance in all of the mean values suggests that there are many factors at the individual level that contribute to delay. The shorter period of delay in congenital cataract patients may be the result of the more rapid onset of signs as well as the likelihood of more severe vision loss. However, even among congenital cataract patients, there is significant variation in the length of delay, particularly among girls. Boys receiving surgery at KCMC generally outnumber girls two to one and it is assumed that this preponderance of boys has more to do with societal expectations of gender roles than any biological reason. ${ }^{79}$

Previous research in Africa among children receiving surgical intervention has been limited by the lack of information about the child before presentation to hospital. One of the most important contributing factors to delay in presentation was proximity to the hospital. This association was particularly important for children with congenital cataract. The Kilimanjaro Centre for Community Ophthalmology initiated "bridging strategies" in 2002; these aimed to address the barriers to use of eye care services in the region. By the end of 2004 the number of cataract surgeries in adults had increased threefold. ${ }^{10}$ Inclusion of promotion of the recognition of the importance of childhood cataract throughout the region in 2003 has led to a twofold increase in childhood cataract surgeries at KCMC Hospital in the last year. There has been no similar programme in the "far" regions. Thus, the association between distance to hospital and delay may partly be a consequence of specific strategies meant to "bridge" communities with the hospital.

In over $85 \%$ of cases, the mother brought the child to hospital. A mother's socioeducational status may contribute to her appreciation of the value of specific healthcare interventions as well as to an increased involvement in decision making within the household. Qualitative data on decision making at the household level are being addressed separately through in-depth interviews with parents at hospital and in the communities.

Parental understanding of the natural growth and development of infants is a function of community norms as well as experience with raising older children. This understanding becomes much more refined after the experience of observing a child progress through stages of infant development. Thus, the finding that children with congenital cataract who had a sibling (an older sibling) were brought to the hospital sooner than congenital cataract cases without a sibling seems logical. It does suggest that there is inadequate community knowledge or family knowledge about expectations of vision in infants. 
Table 3 Characteristics associated with delay in presentation to hospital

\begin{tabular}{|c|c|c|c|c|c|c|c|c|c|}
\hline & \multicolumn{3}{|c|}{ All cataract $(n=178)$} & \multicolumn{3}{|c|}{ Congenital cataract $(n=74)$} & \multicolumn{3}{|c|}{ Developmental cataract $(n=104)$} \\
\hline & \multirow{2}{*}{$\begin{array}{l}\leqslant 12 \\
\text { months }\end{array}$} & \multirow{2}{*}{$\begin{array}{l}>12 \\
\text { months } \\
n=104\end{array}$} & \multirow{2}{*}{$\frac{\text { OR }(95 \% \mathrm{Cl})}{\text { p Value }}$} & \multirow{2}{*}{$\begin{array}{l}\leqslant 12 \\
\text { months }\end{array}$} & \multirow{2}{*}{$\begin{array}{l}>12 \\
\text { months } \\
n=33\end{array}$} & \multirow{2}{*}{$\frac{\text { OR }(95 \% \mathrm{Cl})}{\mathrm{p} \text { Value }}$} & \multirow{2}{*}{$\begin{array}{l}\leqslant 12 \\
\text { months }\end{array}$} & \multirow{2}{*}{$\begin{array}{l}>12 \\
\text { months }\end{array}$} & \multirow{2}{*}{$\frac{\text { OR }(95 \% \mathrm{Cl})}{\mathrm{p} \text { Value }}$} \\
\hline & & & & & & & & & \\
\hline \multicolumn{10}{|c|}{ Sex of child with cataract } \\
\hline Male & $42(42.8)$ & $56(57.1)$ & \multirow[t]{2}{*}{$1.13(0.59$ to 2.14$)$} & $22(59.5)$ & $15(40.5)$ & \multirow[t]{2}{*}{$1.39(0.50$ to 3.87$)$} & $20(32.8)$ & $41(67.2)$ & \multirow[t]{2}{*}{$1.13(0.45$ to 2.85$)$} \\
\hline Female & $32(40.0)$ & $48(60.0)$ & & $9(51.4)$ & $18(48.6)$ & & $13(30.2)$ & $30(69.8)$ & \\
\hline \multicolumn{10}{|c|}{ Age of child with cataract (months) at the time of presentation to hospital } \\
\hline Mean & 37.1 & 86.5 & \multirow[t]{3}{*}{$p<0.001$} & 13.9 & 58.8 & $\mathrm{p}<0.001$ & 65.9 & 99.3 & $p<0.001$ \\
\hline SD & 41.4 & 50.2 & & 20.7 & 45.1 & & 42.8 & 47.3 & \\
\hline Median & 12 months & 84 months & & 8 months & 40 months & & 60 months & 108 months & \\
\hline Distance to $\mathrm{h}$ & ospital & & & & & & & & \\
\hline Near & $45(50.0)$ & $45(50.0)$ & 1.97 (1.02 to 3.79$)$ & $25(73.5)$ & $9(26.5)$ & $3.99(1.33$ to 12.27$)$ & $20(35.7)$ & $36(64.3)$ & $1.45(0.58$ to 3.67$)$ \\
\hline $\begin{array}{l}\text { Far } \\
\text { Travelling }\end{array}$ & $29(33.7)$ & $57(66.2)$ & & $16(41.0)$ & $23(59.0)$ & $p=0.01$ & $13(27.7)$ & $34(72.3)$ & \\
\hline costs & & & & & & & & & \\
\hline$<$ US\$5 & $43(44.7)$ & $53(55.2)$ & $1.33(0.70$ to 2.55$)$ & $24(64.9)$ & $13(35.1)$ & $2.17(0.77$ to 6.18$)$ & $19(32.3)$ & $40(67.8)$ & $1.05(0.42$ to 2.63$)$ \\
\hline$>$ US $\$ 5$ & 31 (37.8) & $51(62.2)$ & & $17(45.9)$ & $20(54.1)$ & & $14(31.1)$ & $31(68.9)$ & \\
\hline Self treatmen & & & & & & & & & \\
\hline Reported & $7(38.3)$ & $11(61.1)$ & $0.88(0.29$ to 2.63$)$ & $3(37.5)$ & $5(62.5)$ & $0.44(0.08$ to 2.38$)$ & $4(40.0)$ & $6(60.0)$ & $1.49(0.32$ to 6.63$)$ \\
\hline Not reported & $67(41.8)$ & $93(58.1)$ & & $38(57.6)$ & $28(42.4)$ & & $29(30.9)$ & $65(69.1)$ & \\
\hline Religion & & & & & & & & & \\
\hline Christian & $46(41.8)$ & $64(58.1)$ & $1.01(0.51$ to 2.00$)$ & $26(57.8)$ & $19(42.2)$ & 1.05 (0.34 to 3.27$)$ & $20(30.8)$ & $45(69.2)$ & $0.93(0.36$ to 2.41$)$ \\
\hline Muslim & $25(41.6)$ & $35(58.3)$ & & $13(56.5)$ & $10(43.5)$ & & $12(32.4)$ & $25(67.6)$ & \\
\hline Who first not & ced the defe & & & & & & & & \\
\hline Caregivers & $54(38.8)$ & $85(61.1)$ & $0.57(0.26$ to 1.25$)$ & $30(52.6)$ & $27(47.4)$ & $0.61(0.17$ to 2.10$)$ & $24(29.3)$ & 58 (70.7) & $0.60(0.20)$ \\
\hline Others & $20(52.6)$ & $18(47.4)$ & & $11(64.7)$ & $6(35.3)$ & & $9(40.9)$ & $13(59.1)$ & \\
\hline Father's socio & educational & status & & & & & & & \\
\hline $\begin{array}{l}\text { Farmer } \\
\text { (illiterate) }\end{array}$ & $5(35.7)$ & $9(64.2)$ & $\chi^{2}($ trend $)=1.78$ & $2(66.7)$ & $1(33.3)$ & $\chi^{2}$ (trend $)=0.68$ & $3(27.3)$ & 8 (72.7) & $\chi^{2}$ (trend $)=0.58$ \\
\hline $\begin{array}{l}\text { Farmer } \\
\text { (educated) }\end{array}$ & $26(35.7)$ & $42(64.3)$ & $p=0.18$ & $15(50.0)$ & $15(50.0)$ & $p=0.41$ & $11(28.9)$ & $27(71.1)$ & $P=0.45$ \\
\hline Business & $38(58.7)$ & $40(51.3)$ & & $22(64.7)$ & $12(35.3)$ & & $16(36.4)$ & $28(63.6)$ & \\
\hline (educated) & & & & & & & & & \\
\hline Age of father & lat time of $c$ & hild's birth) & & & & & & & \\
\hline$<30$ & $23(35.3)$ & $42(64.6)$ & $0.65(0.31$ to 1.32$)$ & $13(50.0)$ & $13(50.0)$ & 0.71 (0.23 to 2.22$)$ & $10(25.6)$ & $29(74.4)$ & $0.59(0.21$ to 1.64$)$ \\
\hline $30+$ & $39(45.8)$ & $46(54.1)$ & & $21(58.3)$ & $15(41.7)$ & & $18(36.7)$ & $31(63.3)$ & \\
\hline Mother's soci & oeducational & status & & & & & & & \\
\hline $\begin{array}{l}\text { Farmer } \\
\text { (illiterate) }\end{array}$ & $9(30.0)$ & $21(70.0)$ & $\chi^{2}$ (trend) $=3.83$ & $6(46.2)$ & $7(53.8)$ & $\chi^{2}$ (trend) $=1.54$ & $3(17.6)$ & $14(82.4)$ & $\chi^{2}($ trend $)=3.04$ \\
\hline Business & $22(52.4)$ & $20(47.6)$ & & $11(68.8)$ & $5(31.3)$ & & 11 (42.3) & 15 (57.7) & \\
\hline (educated) & & & & & & & & & \\
\hline Age of mothe & r lat child's & jirth) & & & & & & & \\
\hline$<30$ & $49(39.5)$ & $75(60.4)$ & $0.62(0.28$ to 1.36$)$ & $30(54.5)$ & $25(45.5)$ & $0.48(0.11$ to 1.96$)$ & $19(27.5)$ & $50(72.5)$ & $0.57(0.20$ to 1.65$)$ \\
\hline $30+$ & $20(51.2)$ & $19(48.7)$ & & $10(71.4)$ & $4(28.4)$ & & $10(40.0)$ & $15(60.0)$ & \\
\hline Laterality of $c$ & ataract & & & & & & & & \\
\hline Bilateral & $30(50.8)$ & $29(49.2)$ & $1.55(0.58$ to 4.17$)$ & $19(70.4)$ & $8(29.6)$ & $1.78(0.24$ to 13.15$)$ & $11(34.4)$ & $21(65.6)$ & $0.98(0.28$ to 3.51$)$ \\
\hline Unilateral & $12(40.0)$ & $18(60.0)$ & & $4(57.1)$ & $3(42.9)$ & & $8(34.8)$ & $15(65.2)$ & \\
\hline Family history & with catara & & & & & & & & \\
\hline Yes & $14(37.8)$ & $23(62.1)$ & $0.82(0.37$ to 1.83$)$ & $8(47.1)$ & $9(52.9)$ & $0.64(0.16$ to 2.47$)$ & $6((30.0)$ & $14(70.0)$ & $0.73(0.18$ to 2.95$)$ \\
\hline No & $60(42.5)$ & $81(57.4)$ & & $18(58.1)$ & $13(41.9)$ & & $10(37.0)$ & $17(63.0)$ & \\
\hline Number of ch & ildren in hou & sehold & & & & & & & \\
\hline $2+$ children & $35(42.2)$ & $48(57.8)$ & 1.05 (0.55 to 1.99$)$ & $22(66.7)$ & $11(33.3)$ & 4.40 (1.38 to 14.39$)$ & $13(26.0)$ & $37(74.0)$ & $0.60(0.24$ to 1.50$)$ \\
\hline Only child & $39(41.0)$ & $56(58.9)$ & & $10(31.3)$ & $22(68.7)$ & $\mathrm{p}<0.01$ & $20(37.0)$ & $34(63.0)$ & \\
\hline Marital status & of parents & & & & & & & & \\
\hline Married & $62(42.1)$ & $85(57.8)$ & $1.38(0.54$ to 3.61$)$ & $37(56.9)$ & $28(43.1)$ & $3.30(0.51$ to 26.8$)$ & $25(30.5)$ & $57(69.5)$ & $0.75(0,24$ to 2.42$)$ \\
\hline $\begin{array}{l}\text { Single/no } \\
\text { parent alive }\end{array}$ & $9(34.6)$ & $17(65.4)$ & & $2(28.6)$ & $5(71.4)$ & & $7(36.8)$ & $12(63.2)$ & \\
\hline
\end{tabular}

We did not find self treatment commonly reported or any association with delay in presentation; this may reflect the hesitancy of parents to report self treatment for fear of being criticised rather than a true lack of association. Information on laterality of cataract was not available from children enrolled at CCBRT and our failure to find an association with laterality may simply reflect the small number of children.

Findings from our study will be limited by sample bias; we could not obtain information on children brought in by teachers from schools for the blind for cataract surgery.

Our findings suggest that delay in presentation for childhood cataract surgery remains a significant problem, even when high quality surgical services are available within relatively easy reach. Improved recognition by health workers will, by itself, be inadequate to address this problem. Reaching children who might be considered "unreachable" because of distance and low socioeducational status of the household will require a more systematic approach to developing bridging strategies that link communities with hospitals. Educational efforts will need to be supplemented with mechanisms for ensuring that children with cataract can reach the hospital in a timely fashion.

\section{ACKNOWLEDGEMENTS}

This project was supported in part by a grant from Seva Canada and programme support from Dark and Light Blind Care. Dr 


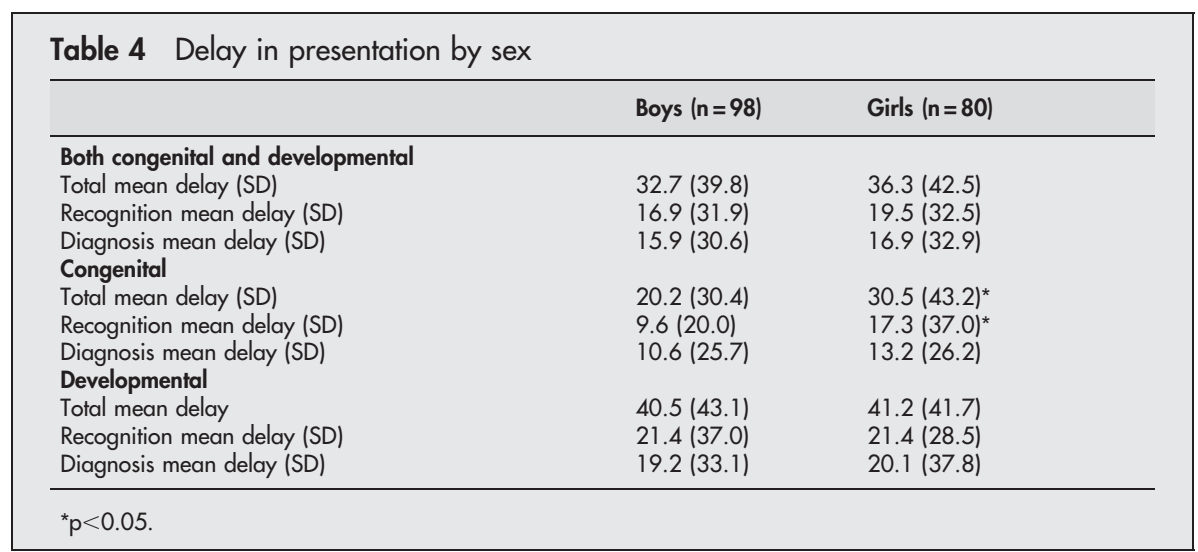

Mwende's dissertation research, which included the first 70 children presented in this study, was also supported by Tumaini University.

\section{Authors' affiliations}

J Mwende, Department of Ophthalmology, Tumaini University/KCMC, Moshi, Tanzania

A Bronsard, M Mosha, R Geneau, P Courtright, Kilimanjaro Centre for Community Ophthalmology, Tumaini University/KCMC, Moshi,

Tanzania

A Bronsard, Department of Anthropology, Université Laval, Quebec,

Canada

R Bowman, CCBRT Hospital, Dar es Salaam, Tanzania

Competing interests: none declared

\section{REFERENCES}

1 Foster A, Gilbert C, Rahi J. Epidemiology of cataract in childhood: a global perspective. J Cataract Refract Surg 1997;23:601-4.
2 Rahi JS, Dezateux C. National cross sectional study of detection of congenital and infantile cataract in the United Kingdom: role of childhood screening and surveillance. The British Congenital Cataract Interest Group. BMJ 1999;318:362-5

3 Gilbert C, Rahi JS, Quinn GE. Visual impairment and blindness in children. In: Johnson GJ, Minassian DC, Weale RA, et al, eds. Epidemiology of eye diseases. London: Arnold Publishers, 2003.

4 Gilbert CE, Vanovas R, Hagan M, et al. Causes of childhood blindness: results from West Africa, South India and Chile. Eye 1993;7:184-8.

5 Gilbert CE, Foster A, Waddel K, et al. Causes of childhood Blindness in East Africa: Results in 491 pupils attending 17 schools for the blind in Malawi, Kenya and Uganda. Ophthalmic Epidemiol 1995;2:77-84.

6 Kello AB, Gilbert C. Causes of severe visual impairment and blindness in children in schools for the blind in Ethiopia. Br J Ophthalmol 2003:87:526-30.

7 Waddel KM. Childhood blindness and low vision in Uganda. Eye 1998; 12:184-92

8 Van Dijk K, Courtright P. Barriers to surgical intervention among blind and low vision children in Malawi. Visual Impairment Res 2000;2:75-9.

9 Yorston D, Wood M, Foster A. Results of cataract surgery in young children in east Africa. Br J Ophthalmol 2001;85:267-71.

10 Lewallen $S$, Roberts $H$, Hall $A B$, et al. Increasing cataract surgery to meet Vision 2020 targets: experience from two rural programmes in east Africa. Br J Ophthalmol 2005;89:1237-40. 